\title{
Knowledge and Rational Drug Use of the Community of Ban Nongyang in Tambon Hua Ruea, Mueang District, Ubon Ratchathani Province, Thailand
}

\section{Thanyasawad T* and Srimoungam W}

Faculty of Nursing, Ratchathani Ubon University, Thailand

*Corresponding author: Thanyasiri Thanyasawad, Faculty of Nursing, Ratchathani Ubon University, 261 Bypass road Chae Ramae District Mueang District, Ubon Ratchathani Province, 34000, Thailand, Tel: 045 - 319900; Email: thanyasiri140955@gmail.com

\section{Research Article}

Volume 4 Issue 1

Received Date: December 16, 2019

Published Date: January 17, 2020

DOI: $10.23880 /$ nhij-16000213

\section{Abstract}

Introduction: WHO defines the rational drug use as 'Using drugs according to the patient's health problem. An appropriate dose is used for individual patients in an appropriate time.' The communities at local and international levels inappropriately spend more than $50 \%$ on drugs. An estimated 35 million people worldwide have suffered thanks to unnecessary drugs. Only one in seven was given appropriate treatment. The consequence was a side effect, drug-related dangers and unnecessary economic loss.

\section{Objective:}

- $\quad$ Aim to study drug knowledge and understanding correctly and safely.

- $\quad$ Aim to assess the practice of using self-medication reasonably

- $\quad$ Aim to compare between knowledge and understanding about medicine and the practice of using self-justifying medicine.

Material \& Methods: A questionnaire was administered to 292 respondents from the communities of Tambon Hua Ruea in Ubon Ratchathani province, Thailand. It was concerned with the subjects' knowledge and behavior in using drugs.

Results: It was found that the respondents were females (59.2\%), aged $61-70$ years (22.95\%), and completed the primary education (60.96\%). They had knowledge and could complete the questionnaire (68.25\%). Their drug-using behavior averaged $2.70 \%$. With knowledge in using drugs and the subjects' behavior in using drugs studied, it was found that age, educational levels, treatment rights and personal disease were statistically different at $\mathrm{p}<.05$.

Conclusion: The medical network has a vital role to play to support the operation. Local mechanisms should be used to solve the problems. Attention should be given to the performance of the local hospital officials in terms of using drugs, and providing counseling. Attention is also to be given to the relations between the service providers and the people who are the recipients of the service.

Discussion: A majority of the subjects did not have a proper knowledge and lacked an understanding concerning the safe drug use. That was due to the patient's drug-using behavior. To tackle the problems, the Hua Ruea Community Hospital conducted the project to launch the rational drug use with the aim to reduce the drug resistance in the patients.

Keywords: Knowledge; Rational Drug Use; Communities; Behavior 


\section{Introduction}

The drug administration in Thailand is a major issue as far as the health system is concerned. The problems related to the drug system include increased spending on drugs, wrong and necessary use of drugs, inaccessibility to drugs, etc. The survey found that there was worryingly high spending on drugs. For more than three decades, the spending on drugs has been steadily increasing. In 2008 alone, up to 272,841 million baht was spent on drugs, accounting for $46.39 \%$ or 3.01 of GDP [1]. The annual rate of drug use is $7-8 \%$ higher than GDP which grows at $5-6 \%$ per year. In 2014, it was found that the value of drug consumption of Thais was hundred billion baht. In this respect, the unnecessary drug use cost up to two billion baht. Use of drugs with suspicious results was four billion baht. Negatively, as many as 38,000 people developed a drug resistance. The spending on drugs is close to the spending on health which is $7-8 \%$ a year. Importantly, irrational drug use was found in all levels ranging from the hospital to the community [1]. For example, people about 40 $-60 \%$ in provincial areas and $70-80 \%$ in Bangkok habitually use antibiotics for a common cold [2].

In 2010, rational drug use was stipulated in the 2010 National Drug Policy. The aim was to encourage the drug use in a rational and valuable fashion. The policy in question has the strategies on the drug use. The strategy no. 3 described the development of mechanism and tools for appropriate and rational drug use [3]. Thanks to that strategy, there came RDU or Rational Drug Use Hospital.

RDU hospital means the treatment site following six policies in promoting the rational drug use. The policies are: 1) strength of the pharmacy and therapeutics committee or PTC, 2) standardization of drugs and labels, and the public's access to drug information, 3 ) essential tools for rational drug use, 4) awareness on the part of medical personnel and medical recipients, 5) medical care for special groups, and 6) promotion of ethics in drug prescription [4-8].

Thailand has operated the RDU hospital project since 2014. Seventy-two hospitals participate in the project. The Ministry of Public Health had come out with the policy on the rational drug use to improve the health service in 2017 [9]. Although their knowledge on the rational drug use has increased, medical personnel do not have an increased awareness in terms of the policy on the rational drug use. It was found that due attention should be given to the following: drug prescription, a handbook on drugs, proper drug use in terms of dose and methods, vigilance in special groups, consideration of the patients' rights [10].

The Hua Ruea Community Health Hospital is the primary service unit providing the health service to the local residents of the surrounding communities. The communities under study have 1477 households from 10 villages and 6,069 inhabitants. The Faculty of Nursing of Ratchathani University, Ubon Ratchathani and the Hua Ruea Health Promotion Hospital had worked together on the health issue. To carry out the project, the fourth-year nursing students from Ratchathani University had worked on the helath issue in Ban Nongyang where 817 local inhabitants lived. Of these residents, 410 were males and 417 were females.

Based on the family visit, it was found that there were patients suffering from chronic illness. They regularly got medicine from the hospital. It was also found that the subjects had little or no knowledge on drug use. In addition, they did not have an understanding of the rational drug use. With the problems found and the significance of the rational drug use realized, the research team aimed to raise an awareness of the rational drug use among the residents in their everyday life and to prevent unnecessary drug use. To achieve the goal, the team conducted the study on knowledge and rational drug use of the communities of Ban Nongyang in Mueang district of Ubon Ratchathani province, Thailand. It is expected that acquired data can be utilized to develop the rational drug use in the communities in question [11-13].

\section{Material \& Methods}

The samples were 817 residents of Ban Nongyang, derived by the Krejcie and Morgan's table. Some subjects were excluded by $10 \%$. Hence the samples in the study stood at 292. Importantly, the samples in the research were to be literate and help themselves. Independent variables were sex, age, educational levels, occupations, monthly incomes, status, and treatment rights. Dependent variables were medicinal knowledge and behavior in self-medication. The research instrument was a questionnaire.

The average evaluation was based on the concept of Boonchom Sisa-ard (2009: 103). In evaluating the instrument, Likert's five-rating scale was employed with the following criteria: 4.50 - 5.00 means self-medication/care at the highest level (5), $3.51-4.50$ means self-medication/care at a high level (4), 2.51 -3.50 means self-medication/care at a moderate level (3), $1.51-2.50$ means self-medication/care at a low level (2), and $0.00-1.50$ means self-medication/care at the lowest level (1).

- Data Analysis

- Personal factors were sex, age, marital status, educational levels, occupations, status, rights to treatment, and diseases suffered by individuals. Statistics used were frequency, percentage, means, standard deviation.

- Dependent and independent variables were analyzed by one-way ANOVA Tables 1-5. 


\section{Results}

\begin{tabular}{|c|c|c|c|}
\hline \multirow{2}{*}{ Characteristics } & \multicolumn{3}{|c|}{ Respondents } \\
\hline & Category & Frequency & Percentage \\
\hline \multirow{2}{*}{ Gender } & Male & 119 & $40.80 \%$ \\
\hline & Female & 173 & $59.20 \%$ \\
\hline \multirow{4}{*}{ Age } & below 20 & 16 & $5.48 \%$ \\
\hline & $21-40$ & 79 & $27.05 \%$ \\
\hline & $41-60$ & 96 & $32.88 \%$ \\
\hline & Above 60 & 101 & $34.59 \%$ \\
\hline \multirow{6}{*}{ Education } & Primary & 178 & $60.95 \%$ \\
\hline & secondary & 37 & $12.67 \%$ \\
\hline & high school & 51 & $17.47 \%$ \\
\hline & Bachelor degree & 15 & $5.14 \%$ \\
\hline & Master & 1 & $0.34 \%$ \\
\hline & others & 10 & $3.43 \%$ \\
\hline \multirow{6}{*}{ occupation } & Trader & 38 & $13.01 \%$ \\
\hline & farmers & 161 & $55.14 \%$ \\
\hline & state officials & 6 & $2.05 \%$ \\
\hline & casual employment & 36 & $12.33 \%$ \\
\hline & no employment & 19 & $6.51 \%$ \\
\hline & Others & 32 & $10.96 \%$ \\
\hline \multirow{6}{*}{ Income } & $<1000$ b. & 46 & $15.75 \%$ \\
\hline & $1000-5000 \mathrm{~b}$. & 135 & $46.23 \%$ \\
\hline & $5001-10,000 \mathrm{~b}$. & 73 & $25 \%$ \\
\hline & $10,000-50,000 \mathrm{~b}$. & 34 & $11.64 \%$ \\
\hline & $50,001-100,000 \mathrm{~b}$. & 3 & $1.03 \%$ \\
\hline & $>100001 \mathrm{~b}$. & 1 & $0.34 \%$ \\
\hline \multirow{4}{*}{ Status } & Married & 222 & $76.00 \%$ \\
\hline & Separated & 6 & $2.10 \%$ \\
\hline & divorced & 10 & $3.40 \%$ \\
\hline & Single & 54 & $18.50 \%$ \\
\hline \multirow{4}{*}{ Treatment Rights } & 30-baht health care scheme & 260 & $89.00 \%$ \\
\hline & Federal finance & 6 & $2.10 \%$ \\
\hline & Social security & 25 & $8.60 \%$ \\
\hline & Others & 1 & $0.34 \%$ \\
\hline \multirow{2}{*}{ Chronic Disease } & Yes & 76 & $26.00 \%$ \\
\hline & No & 216 & $74.00 \%$ \\
\hline
\end{tabular}

Table 1: Number, Percentage, general characteristics of the community of Ban Nongyan, N=292. 


\section{Knowledge on medication}

\begin{tabular}{|c|c|c|c|}
\hline \multicolumn{2}{|c|}{ Right item } & \multicolumn{2}{|c|}{ Wrong item } \\
\hline Number & Percentage & Number & Percentage \\
\hline 212 & 72.6 & 80 & 27.4 \\
\hline 101 & 34.6 & 191 & 65.4 \\
\hline 99 & 33.9 & 193 & 66.1 \\
\hline 104 & 35.6 & 188 & 64.4 \\
\hline 158 & 54.1 & 134 & 45.9 \\
\hline 215 & 73.6 & 77 & 26.3 \\
\hline 146 & 50 & 146 & 50 \\
\hline 111 & 38 & 181 & 62 \\
\hline 236 & 80 & 56 & 19.2 \\
\hline 115 & 39.4 & 177 & 60.6 \\
\hline 249 & 85.3 & 42 & 14.4 \\
\hline 259 & 88.7 & 33 & 11.3 \\
\hline 257 & 88 & 35 & 12 \\
\hline 173 & 59 & 119 & 40.8 \\
\hline 172 & 58.9 & 120 & 41.1 \\
\hline 240 & 82.2 & 52 & 17.8 \\
\hline 201 & 68.8 & 91 & 31.2 \\
\hline 27 & 9.2 & 265 & 90.8 \\
\hline 56 & 19.2 & 236 & 80.8 \\
\hline 13 & 4.5 & 279 & 95.5 \\
\hline
\end{tabular}

1. Antacids as prescribed by a doctor can reduce the burning symptom in stomach.

2. Keeping a medicine in the form of jell or wax in the fridge can prolong its expiry date.

3. Keeping medicine in the form of syrup in the fridge can prolong its expiry date.

4. The eye-drop once used can be kept for further uses to its expiry date.

5. Acne medication mixed with antibiotics can be used to treat all kinds of acne.

6. Taking antibiotics should be done at least five days in succession.

7. Mineral powder can be used to treat stomach ache.

8. Paracetamol can relieve/reduce cold.

9. One should chew the pills before swallowing it to make it more effective.

10. Vitamin is the food supplement. Thus, excessive intake of it is not dangerous to health.

11. Taking medicine before food means taking it 30-60 minutes before food.

12. An after-food medicine should be taken 15-30 minutes after food.

13 Some anti-allergic medicine may make us sleepy.

14. Calamine lotion is for external use and for skin wounds.

15 Laxatives have medicinal property in reducing bodily weight.

16. Taking excessive paracetamol can affect one's liver.

17. If one forgets to take medicine, one should double the dose next time.

18. Prior to buying medicine, one has to check the production or expiry date.

19. One should not drink milk, tea or coffee when one takes medicine.

20 When one develops an allergy to medicine, one must stop taking it immediately.

Table 2: Number, Percentage of knowledge on the drug use in a correct and safe manner of the community of Ban Nongyang, $\mathrm{N}=292$.

\begin{tabular}{|c|c|c|c|}
\hline Behavior in using drugs & X & SD & level \\
\hline \multicolumn{4}{|l|}{ Self-care during illness } \\
\hline 1. You go to a pharmacist for counseling. & 2.63 & 1.222 & moderate \\
\hline 2. If given a prescription, you go to the pharmacy where a pharmacist is in charge. & 2.93 & 1.271 & Moderate \\
\hline 3.You choose to buy medicine from the drug store where the pharmacist is in charge. & 3.06 & 1.315 & Moderate \\
\hline means & 2.87 & 1.269 & Moderate \\
\hline \multicolumn{4}{|l|}{ Rational drug use } \\
\hline 4. You give the medicine you use to others suffering from the same disease. & 2 & 1.02 & Low \\
\hline 5. You try the medicine as recommended by your friend when you are sick. & 1.86 & 0.989 & Low \\
\hline
\end{tabular}




\begin{tabular}{|l|c|c|c|}
\hline $\begin{array}{l}\text { 6. You will use the same old medicine you have long kept if you have the same symp- } \\
\text { tom. }\end{array}$ & 2.17 & 1.137 & Low \\
\hline 7. You stop taking antibiotics if you feel better or if your symptoms improve. & 2.7 & 1.287 & Moderate \\
\hline 8. If you feel something wrong after taking medicine, you will stop it immediately. & 3.61 & 1.372 & High \\
\hline 9. You increase the higher dose than recommended to recover more quickly. & 2.12 & 1.282 & Low \\
\hline Means & $\mathbf{2 . 4 1}$ & $\mathbf{1 . 1 8 1}$ & Low \\
\hline \multicolumn{4}{|c|}{ Getting counseling on drug use from a pharmacist } \\
\hline 10. You will consult a pharmacist when you are given some special medicines. & 3.05 & 1.273 & Moderate \\
\hline 11. You will consult a pharmacist if you are given a new drug you never have before. & 3.6 & 2.026 & High \\
\hline Means & 3.33 & 1.6495 & Moderate \\
\hline
\end{tabular}

Table 3: Number, Percentage, Means and Standard Deviation of Behavior in using drugs in a rational way of the Community of Ban Nonyang. $\mathrm{N}=292$

\begin{tabular}{|c|c|c|c|c|c|c|}
\hline General characteristics & Source of variation & df & SS & MS & $\mathbf{F}$ & $\mathbf{P}$ \\
\hline \multirow{3}{*}{ age } & between groups & 63 & 3519.27 & 55.861 & & \\
\hline & within groups & 228 & 10704.8 & 46.951 & & \\
\hline & Total & 291 & 14224.1 & & 1.19 & 0.18 \\
\hline \multirow{3}{*}{ Sex } & between groups & 1 & 26.966 & 26.966 & & \\
\hline & within groups & 290 & 14197.1 & 48.956 & & \\
\hline & total & 291 & 14224.1 & & 0.55 & 0.46 \\
\hline \multirow{3}{*}{ Educational Levels } & between groups & 6 & 170.666 & 28.444 & & \\
\hline & within groups & 285 & 14053.4 & 49.31 & & \\
\hline & total & 291 & 14224.1 & & 0.58 & 0.75 \\
\hline \multirow{3}{*}{ occupations } & between groups & 5 & 87.07 & 17.414 & & \\
\hline & In groups & 286 & 14137 & 49.43 & & \\
\hline & Total & 291 & 14224.1 & & 0.35 & 0.88 \\
\hline \multirow{3}{*}{ Status } & between groups & 4 & 341.401 & 85.35 & & \\
\hline & within groups & 287 & 13882.7 & 48.372 & & \\
\hline & Total & 291 & 14224.1 & & 1.76 & 0.14 \\
\hline \multirow{3}{*}{ Family incomes } & between groups & 36 & 1722.8 & 47.855 & & \\
\hline & Within groups & 255 & 12501.3 & 49.025 & & \\
\hline & Total & 291 & 14224.1 & & 0.98 & 0.51 \\
\hline \multirow{3}{*}{ Treatment rights } & between groups & 3 & 338.56 & 112.853 & & \\
\hline & Within groups & 288 & 13885.5 & 48.214 & & \\
\hline & Total & 291 & 14224.1 & & 2.34 & 0.07 \\
\hline \multirow{3}{*}{ personal disease } & between groups & 1 & 129.054 & 129.054 & & \\
\hline & Within groups & 290 & 14095 & 48.604 & & \\
\hline & Total & 291 & 14224.1 & & 2.66 & 0.1 \\
\hline
\end{tabular}

Table 4: The result of a comparison of differences in behaviors in using drugs in a rational way as classified by the general characteristics of the sample groups.

$\mathrm{df}=$ degree of freedom, $\mathrm{SS}=$ Sum Square, $\mathrm{MS}=$ Mean square, $\mathrm{F}=$ Statistical value , P=Probability Value ( $p$-value) 


\begin{tabular}{|c|c|c|c|c|c|c|}
\hline General characteristics & Sources of variation & df & SS & MS & $\mathbf{F}$ & $\mathbf{P}$ \\
\hline \multirow{3}{*}{ Age } & Between groups & 63 & 614.408 & 9.753 & & \\
\hline & within groups & 228 & 1399.383 & 6.138 & & \\
\hline & Total & 291 & 2013.791 & & 1.589 & $.008^{* *}$ \\
\hline \multirow{3}{*}{ Sex } & between groups & 1 & 0.081 & 0.081 & & \\
\hline & within groups & 290 & 2013.71 & 6.944 & & \\
\hline & Total & 291 & 2013.791 & & 0.012 & 0.914 \\
\hline \multirow{3}{*}{ Educational levels } & between groups & 6 & 108.458 & 18.08 & & \\
\hline & Within groups & 285 & 1905.333 & 6.685 & & \\
\hline & Total & 291 & 2013.791 & & 2.704 & $.014^{* *}$ \\
\hline \multirow{3}{*}{ Occupations } & between groups & 5 & 18.251 & 3.65 & & \\
\hline & within groups & 286 & 1995.54 & 6.977 & & \\
\hline & total & 291 & 2013.791 & & 0.523 & 0.759 \\
\hline \multirow{3}{*}{ Status } & between groups & 4 & 26.357 & 6.589 & & \\
\hline & within groups & 287 & 1987.434 & 6.925 & & \\
\hline & total & 291 & 2013.791 & & 0.952 & 0.435 \\
\hline \multirow{3}{*}{ Family incomes } & between groups & 36 & 174.784 & 4.855 & & \\
\hline & within groups & 255 & 1839.007 & 7.212 & & \\
\hline & Total & 291 & 2013.791 & & 0.673 & 0.923 \\
\hline \multirow{3}{*}{ Treatment rights } & between groups & 3 & 58.082 & 19.36 & & \\
\hline & within groups & 288 & 1955.709 & 6.791 & & \\
\hline & total & 291 & 2013.791 & & 2.851 & $.038^{* *}$ \\
\hline \multirow{3}{*}{ Personal diseases } & between groups & 1 & 26.846 & 26.85 & & \\
\hline & within groups & 290 & 1986.945 & 6.852 & & \\
\hline & Total & 291 & 2013.791 & & 3.918 & $.049 * *$ \\
\hline
\end{tabular}

Table 5: The result of a comparison of the differences in using drugs in a rational manner as classified by the general characteristics of the groups.

\section{Discussion}

It was found that the subjects had a Moderate level of knowledge $70.23 \%$ regarding the drug use. The findings are supported by Chat chai Khawaeaw [14] found that 60.27percent the knowledge of Drug use of the population Most of them had knowledge about medication use at a moderate level,. While the findings are supported by Parinda Isaroon [15] found that the sample group has an average score of $12.55 \pm 2.86$ from a full score of 20 , indicating that there is a moderate level of knowledge. This may be due to the fact that they have little or no access to the information on drugs. A majority of the samples have to rely on the explanation and counseling from medical officials. They have little knowledge in using modern technology to search for information by them. Hence, it is essential to resort to other means to help them in this regard and make them aware of the right method in using drugs. It is important for them to know how to use drugs appropriately. In addition, they have to realize their own rights to treatment, rights to protection and their own behaviors in using drugs. Their awareness in these aspects should be raised as much as possible. The study also found that the behavior in using drugs for selfmedication purpose was at a moderate level. The findings are supported by Dow Rung, et al. [16] found that $82.8 \%$ of the subjects had good drug use behaviors. Only 17.2 percent were at a moderate level. They should be involved to get counseling from a pharmacist when they want to buy a medicine for their chronic disease. They are to be taught how to properly behave when it comes to using drug in a safe and right manner.

\section{Conclusion}

The general public has to be equipped with information on health. Follow-up, evaluation and access to information 
for the public and improvement of the service system are all important. The medical network has a vital role to play to support the operation. Local mechanisms should be used to solve the problems. Attention should be given to the performance of the local hospital officials in terms of using drugs, and providing counseling. Attention is also to be given to the relations between the service providers and the people who are the recipients of the service WHO [17-19].

\section{References}

1. (2013) HITAP (online), available at www. ph.mahidol. ac.th/research/thai/Training/Research Care \& Talk / 3-2556.

2. Puppha Sirirasami (1997) Reports on the Health Behaviors in Using Antibiotics of the Public in Nakornpathom Province. Mahidol University.

3. Pison Jongtrakul (2014) The Hospital's Promotion of the Rational Drug Use. Pharmacy Journal 37(1): 48-62.

4. (2016) The Administrative Department. Rational Drug Use. Nonthaburi: Public Health Ministry.

5. (2011) The Committee on the National Drug System Development 2010. Sahapan Printing Press.

6. (2010) The Working Committee for Development of the System and Man force on Health for Rational Drug Use, April.

7. (2015) The Sub-Committee for Promotion of the Rational Drug Use, a Handbook for Drugs. Bangkok: Thailand Agricultural Council Press.

8. (2011) The Committee for the National Drug Development, 2011. The National Drug Policy 2011. Bangkok: Cooperative Community Press.
9. (2009) Institute of the Public Health System Research. Value of the Domestic Drug Consumption.

10. Tohchoo S, Muenpa R (2016) Results of the Implementation in Using Drugs Rationally by the Hospital in Nonghong District, Buriram Province.

11. Tepaksorn P (2013) Knowledge on Drugs. Office of the Secretariat of Public Health Ministry, 2014. Marayat Yotongyot and Pranee Sawadisan. Determining the Sample for Research.

12. (2018) Hua Ruea Health Promotion Hospital, Geography Information System.

13. Wibulprasert S (2006) Thai Public Health. Office of Policy and Strategies of Public Health Ministry.

14. Khawaeaw CC (2017) Safe rational drug use in the community. Ban Thung Naree Health Promoting Hospital Phatthalung.

15. Isaroon P (2013) Survey of drug knowledge and self-medication practice of first year students at Srinakharinwirot University.

16. Khamwong DR, Sookkhawatwat $T$ (2012) Factors affecting drug use behavior of village health volunteers Chonburi Province. Thai Pharmaceutical and Health Science Journal 7(3): 121-126.

17. (2002) WHO Promotion of the Rational Drug Use: Main Components.

18. WHO (2006) Progress in the rational use of medicines: Report by the secretariat. WHO 60th World Health Assembly. Provisional agenda item, World Health Organization 12.17.

19. WHO (2010) Medicines: rational use of medicines, World Health Organization, Fact sheet No. 338. 